\title{
(2)
}

\section{PODER LOCAL, CIUDADANÍA Y MUNICIPIO: EL PARTIDO REGIONALISTA DE MAGALLANES (1932-1952)}

\author{
Andrés Rojas Böttner. ${ }^{3}$
}

\section{RESUMEN}

El presente artículo aborda un tipo específico de propuesta regionalista, de carácter político, en torno a la trayectoria del Partido Regionalista de Magallanes, cuya fuerza electoral y base programática se relacionó directamente con un fuerte movimiento ciudadano y la politización del descontento local respecto de las prácticas centralistas del Estado chileno en su época. Dentro de sus postulados federalistas, se reivindicaba la relevancia del municipio, el cual se situaba como eje del desarrollo comunal, de resolución adecuada a los problemas locales e instancia de participación ciudadana. En razón de ello, en sus veinte años de presencia política, estableció como prioritario el rol dentro del municipio, incluso sacrificando otras contiendas electorales en su política de alianzas.

Palabras clave: Regionalismo - Municipio - Autonomía - Territorio - Magallanes.
Local power, citizenship and municipality: The trajectory of Regionalist Party of Magellan (1932-1952).

\section{ABSTRACT}

The present article approaches a specific political type of regionalist proposal around the path of the $\mathrm{Re}$ gionalist Party of Magellan, whose electoral strength and programmatic basis had direct relationship with a strong citizen movement and a political assumption of the local dissatisfaction concerning the centralist practices of the Chilean State in the epoch. Within its federalistic postulates, it claimed the importance of the municipality like an axis of the communal development, of suitable resolution of local problems and an instance of citizen participation. In reason of this, in its twenty years of political presence, established like a priority the role of the municipality, even sacrificing other electoral contentions in its politics of alliances.

Key words: Regionalism - Municipality - Autonomy - Territory - Magellan. 


\section{INTRODUCCIÓN}

El centralismo en Chile, lejos de surgir de una tendencia espontánea o natural de administrar el poder desde la Capital, o fruto de una deliberación ciudadana, es el resultado de una paulatina y tensionada construcción histórica, encabezada por la élite del Valle Central. Para ello, se procedió a desestructurar los poderes locales, la participación política y sus órganos representativos (Cabildos, luego Municipios), de larga tradición colonial (Salazar, 2005).

Luego de lograda la Independencia política, una serie de proyectos entraron en pugna durante una década por la definición de la arquitectura del Estado. Uno de los puntos contenciosos fue el rol de las Provincias en la distribución del poder político. ¿Estado Unitario o Federal, Gobierno Conservador o Liberal, Ejecutivo fuerte o débil? fueron algunas de las principales dicotomías en juego. Finalmente, el debate fue zanjado militarmente en 1830 en la Batalla de Lircay, donde el bando conservador resultó vencedor, imponiendo el llamado Estado Portaliano, consagrado en la Constitución de 1833. Dicho ordenamiento derivó en un gobierno fuerte, autoritario y centralista, apoyado principalmente por la élite del Valle Central.
Los constantes conflictos políticos y militares entre la Capital y las Provincias durante el siglo XIX reflejan lo difícil y tenso que resultó fortalecer ese tipo de Estado. Las guerras civiles de 1851 y 1859 no lograron impedir que Santiago se consolidara como el polo privilegiado del Estado Oligárquico, desde el cual pudo concentrar notoriamente la inversión pública (López, 2010), controlar los principales cargos en el Estado y restar autonomía a los poderes locales.

En líneas generales, la arquitectura del Estado se sustentó en un Ejecutivo fuerte, con Intendentes nominados y dependientes del propio presidente, con un Legislativo controlado mediante listas de candidatos oficiales, voto censitario e inexistencia de un verdadero sistema de partidos. De esa manera, la élite de Santiago consolidó paulatinamente su posición a costa de los habitantes del resto del territorio (Salazar, 1998), incluso luego de la caída del Estado Portaliano y la implementación de la estrategia industrialista de mediados del siglo XX (E. Valenzuela, 1999), que tendió a concentrar el mayor gasto público en los ministerios y corporaciones, erosionando todavía más las atribuciones municipales (A. Valenzuela, 1977).

Una de las principales críticas al centralismo es que las decisiones importantes se toman en Santiago de manera 'general', aplicando en la práctica un lógica homogeneizadora que toma por modelo el propio contexto de Santiago como el estándar, desconociendo las múltiples particularidades, necesidades y prioridades de los "beneficiarios" de un programa o inversión pública, en un país con extremos tan distantes. 
Este malestar resultó particularmente grave en la zona austral de Chile, territorio que se hizo a sí mismo a costa de esfuerzo y rigor; el cual, frente a una serie de políticas perjudiciales, el abandono del Gobierno Central y el desconocimiento de su especificidad, va a dar paso, a uno de los primeros partidos regionalistas de la historia de Chile.

\section{AUGE Y CRISIS DE UNA SOCIEDAD}

El territorio austral chileno fue de tardía anexión (1843). Las difíciles condiciones climáticas y de conexión con el resto del territorio lo mantuvieron prácticamente despoblado, a excepción de los pueblos originarios canoeros y pedestres de la zona. Inicialmente, se utilizó como paraje penal, para que posteriormente, tras casi veinte años, se le asignara la categoría de Zona de Colonización; es decir, la de un territorio especial, jerárquicamente inferior al resto del territorio y sin representación política.

Principalmente por criterios geopolíticos, había que ejercer presencia efectiva en el territorio meridional para impedir su ocupación por alguna potencia extranjera. Sin embargo, existía poco interés, por lo que fue necesaria una política de incentivos, generando un mecanismo de atracción de colonos.

Lamentablemente, el incentivo resultó a la larga perjudicial para el desenvolvimiento armónico y equilibrado del territorio austral, ya que se basó en la concesión de grandes extensiones de estepa magallánica, a bajo costo y por un lapso prolongado (20 años), similar a la enfiteusis aplicada en Argentina tiempo antes. Al igual que en dicha nación, ese mecanismo generó en la zona austral una concentración excesiva de la propiedad de la tierra.

A pesar de esta estructura productiva, Magallanes y su principal ciudad, Punta Arenas, desde fines del siglo XIX presentaron un despegue económico de importancia (Martinic, 1988), que los transformó en un centro ganadero y portuario destacado. Este auge económico propició una nutrida inmigración europea y nacional. En el grupo europeo destacaron en número los croatas; dentro de los nacionales, los chilotes (Rivas, 2009).

Conviene explicar las principales razones del éxito económico de fines del siglo XIX. En primer lugar, en 1867, como medida complementaria a la entrega de tierras, se dotó a Punta Arenas, principal puerto de la zona, la categoría de Puerto Libre, es decir, fue favorecido con la exención de los derechos aduaneros, lo que generó un fluido comercio marítimo que contribuyó a morigerar el aislamiento territorial.

En segundo lugar, y en relación con lo anterior, la posición privilegiada de Punta Arenas respecto al estrecho de Magallanes, por entonces zona obligada de paso para el comercio interoceánico de la época, la convirtió en un puerto dinámico. En sus muelles se recibían cientos de buques por temporada, incluso, llegando a niveles cercanos a los de Valparaíso (3/4 en 1906), puerto principal de Chile (Martinic, 1988:16).

Por último, los frutos que arrojaron las medidas acertadas por parte de los estancieros (mejora genética del ganado) y las inversiones realizadas para poder abordar mercados extranjeros de importancia (frigoríficos), 
permitieron un desarrollo sustantivo del importante sector ganadero (Calderón, 1936). Sin embargo, pese a su auge económico, Magallanes continuaba siendo una zona desconocida y abandonada por el centro político, sin instancias de interlocución ni participación política. Normalmente, la máxima autoridad política (Gobernador) era el Jefe Militar del Regimiento, símbolo del poco interés del Gobierno Central.

En la década de 1910, un conjunto de medidas desfavorables para los intereses magallánicos comenzó a preparar el terreno para una profunda crisis económica, que se desató con todo el rigor en la década siguiente. En especial, interesa relevar las medidas provenientes del propio Gobierno, que permiten entender la dinámica política posterior y la constante crítica al desconocimiento de la realidad magallánica de parte del centro político. En 1912, el Gobierno de Chile decide retirar el estatus de Puerto Libre a Punta Arenas, en una época que se consolidaba como el núcleo económico del territorio patagónico binacional, afectando directamente el precio de los productos importados, que en la zona eran la gran mayoría. Poderosos gremios empresariales habían presionado para ello (Sociedad de Fomento Fabril - Sofofa, Sociedad Nacional de Agricultura - SNA).

Un año después, también bajo la presidencia de Barros Luco, el gobierno decidió renovar las concesiones territoriales al reducido grupo estanciero por otros 15 años más, desatando la molestia de la ciudadanía austral, puesto que se confiaba que se pondría fin a la nefasta concentración de la propiedad, que generaba una serie de perjuicios. Por ejemplo, el esque- ma dual de concentración/ exclusión de la propiedad de la tierra impidió la formación de una clase media rural, que probablemente hubiera atemperado la polarización y conflictividad que caracterizó a la provincia en la segunda mitad de la década de 1910. Tampoco permitía negociar salarios, debido a la imposibilidad práctica de constituir sindicatos. Se dificultaba la conformación de familias, debido a las distancias y el predominio masculino dentro de las estancias.

Por último, un imponderable externo. La entrada en vigencia del Canal de Panamá (1914), desvió la mayor parte del tránsito interoceánico hacia Centroamérica. El puerto de Punta Arenas perdió notorio dinamismo, recordando, además, que apenas dos años antes había perdido la exención aduanera.

\section{MAGALLANES: LA LUCHA CÍVICA POR EL RECONOCIMIENTO}

Frente a este contexto de crisis, la sociedad magallánica reaccionó. Su sólida tradición asociativa, sus jerarquías sociales menos rígidas y un grado de educación comparativamente mayor al resto del país (Navarro, 1907), llevó a los vecinos a responder cívicamente. Importantes campañas y manifestaciones acontecieron en distintos momentos, respecto a la revocatoria del Puerto Libre y la renovación de las concesiones de tierras (Martinic, 1992). Sin embargo, institucionalmente eran de 'segunda categoría', y por muy masivas que se presentaran las demandas, éstas no contaban con un órgano coordinador y representativo de los intereses ciudadanos. 
Como Zona de Colonización, no se contaba con alcaldes electos popularmente y mucho menos con representación parlamentaria. La gran lucha, entonces, fue por lograr el estatus de Provincia. Organizados en torno a medios de comunicación y agrupaciones cívicas, se presionó constantemente, logrando posicionar ésta y demás demandas en miembros del Congreso, autoridades políticas y militares en la zona e incluso se concretaron 'misiones' a Santiago para obtener atención de parte del Gobierno Central (Martinic, 1992).

Tras años de intermitentes manifestaciones ciudadanas, se logró finalmente, en 1929, el estatus de Provincia para Magallanes, lo que debía significar además de representación política, una mayor atención y presencia en la zona de las instituciones del Estado. Sin embargo, la gravedad de la crisis socio-económica hizo que la conquista se volviera insuficiente. Gracias al espíritu cívico alcanzado, esa verdadera marea de participación ciudadana se apoyó en el sentimiento anti-centralista y en una sólida identidad en común. Aquella experiencia resultó trascendental para la creación del Partido Regionalista de Magallanes.

\section{EL PARTIDO REGIONALISTA DE MAGA- LLANES}

El Partido Regionalista de Magallanes (PRM) surge en 1932, como una plataforma política ampliada de una organización llamada Legión Cívica de Magallanes, creada meses antes por un grupo de ciudadanos que tenían como objetivo contribuir al progreso de la alicaída zona austral ${ }^{4}$. Conformado principalmente por miembros de la clase media urbana, con gran presencia de inmigrantes europeos/ descendientes y algunos sectores obreros, el partido se presentó como una instancia de coordinación de las demandas ciudadanas y los intereses locales.

El surgimiento del PRM se debe entender como una reacción de auto-organización vecinal ${ }^{5}$ frente a reiterados problemas comunes, desatendidos y olvidados por el vertical y rígido Estado Centralista. Rápidamente se entendió que se requería un nivel superior de institucionalización para enfrentar la que se consideraba fuente de las malas decisiones respecto al territorio: el centralismo. De lo que se trataba era de encarar políticamente el problema y así lo hicieron, con la generación de este partido.

4 Ambas agrupaciones, la Legión y el PRM, se mantuvieron en paralelo estrechamente ligadas. La diferencia radicó en que la Legión se pensó como una instancia más restrictiva (y más elitista probablemente) puesto que establecía como requisito para ingresar a ella haber nacido en Magallanes o bien haber vivido en ella desde por lo menos veinte años. El Partido, en cambio, establecía en sus bases que podían ingresar magallánicos, extranjeros y personas en general simpatizantes de la causa regionalista. (La Voz de Magallanes, 18.07.1932)

5 La palabra vecino originalmente se refería a todos quienes tuvieren 'asiento' en la ciudad y por ende interés en su buen funcionamiento, con el Cabildo como núcleo organizativo. Esa palabra sufrió una erosión conceptual hasta llegar a nuestros días a ser algo más que una mera referencia de distancia en el habitar. 
Ideológicamente, el PRM es un partido difícil de clasificar. En líneas generales se le puede considerar un partido de centro o moderado, que incluso en sus inicios se presentó como ajeno a ideologías izquierda-derecha. De hecho, explícitamente se señala en su programa que "[...] por su naturaleza y orientación no cabe pensar [...] en la llamada 'lucha de clases', por cuanto se hayan comprendidos en él los intereses generales de la región sin distinción de especie alguna." (La Voz de Magallanes, 22.10.1932)

A pesar de ello, a lo largo de su trayectoria de más de 20 años, logró tejer efímeras alianzas con prácticamente todo el espectro político, mostrando un alto grado de pragmatismo y priorizando notoriamente la disputa por el poder municipal.

Dentro de los planteamientos más importantes de su programa (PRM, 1932), es posible mencionar:

- Una modificación constitucional que permita el tránsito del sistema unitario a un régimen federal. Dicha propuesta incluye la existencia de una Constitución Provincial, como marco de la administración territorial, "[...] debiendo dejarse a la provincia todos aquellos deberes, facultades y poderes que por la Constitución Nacional no se entreguen expresamente a las autoridades centrales del país."

Se debe destacar el descreimiento en el modelo unitario y la justificación de su propuesta en párrafos tales como: "[...] La experiencia demuestra que, aun cuando se aplicara prácticamente la descentralización administrativa indicada en la Constitución vigente u otra descentralización semejante, ella sería insuficiente para reaccionar contra nuestras particularidades, que requieren una legislación especial."

- Para llevar a cabo la administración del territorio, se aspira a la formación de comunas autónomas, con elecciones populares e independientes del Poder Ejecutivo.

- Plan progresivo de subdivisión de tierras estatales,

“[...] cuyo manejo debe quedar entregado a las autoridades provinciales, con prescindencia total del Gobierno Central. Este plan de desarrollará a base cooperativo [sic] de instalación y explotación para los pequeños estancieros agrícolaganaderos a quienes se entregarán las mejores tierras, directamente y sin necesidad de subasta, atendiendo solo a las condiciones y antecedentes personales del beneficiado; y a base de subasta pública para las explotaciones mayores, donde predomine el capital sobre el trabajo individual."

- Asimismo, regularización y conservación de las tierras para aquellos que habiéndolas trabajado correctamente carecieran de títulos legales.

- Supresión de la aduana y mayor integración con la Patagonia argentina, mediante "[...] convenios de intercambio de productos regionales con el territorio argentino limítrofe desde Rivadavia hasta Ushuaia."

- Medidas de fomento industrial, minero y turístico, reinicio de las actividades petroleras e instalación de una refinería en la Provincia. 
- Disposición municipal de los ingresos generados en el territorio, "salvo la cuota razonable que reconoce debe pagar a los servicios generales de la Nación."

- Ampliación de las leyes sociales e instalación de secciones independientes de organismos destinados al beneficio y protección de las personas.

- Ajuste de las remuneraciones de empleados fiscales, municipales y de beneficencia de acuerdo a las necesidades de la región.

- Creación de un "Tribunal Superior de Alzada organizado para conocer en última instancia de los recursos de que son susceptibles las resoluciones judiciales, emanadas tanto de los tribunales ordinarios como del trabajo, a fin de terminar con la verdadera denegación de justicia que entraña el sistema actual."

A partir de este programa, es posible concluir la gran confianza y expectativas depositadas por el Partido Regionalista de Magallanes en la autonomía local. Al mismo tiempo, se aprecia una gran desconfianza de sus integrantes en las promesas y el actuar de las autoridades políticas del gobierno central. No se trata de una percepción infundada, debido a una serie de arbitrariedades y situaciones irregulares que se venían dando, como por ejemplo, reparticiones de tierra efectuadas de manera poco transparente y a personas que nada tenían que ver con el territorio. El análisis realizado de las actas municipales en parte del período, demuestra eternas dilaciones e incumplimientos de parte de las distintas autoridades políticas con respecto al reparto del territorio.
Incluso la figura del propio Presidente de la República cayó en cierto descrédito, especialmente bajo el segundo gobierno de Arturo Alessandri (19321938), quien fue incapaz de aplicar lo que años antes había promulgado (Asambleas Provinciales, en la Constitución de 1925) y menos actuó con la prudencia necesaria, como se verá luego.

El órgano de prensa del partido, La Voz de Magallanes, expresaba en sus distintas portadas, tres 'lemas' recurrentes que grafican plenamente lo señalado:

"Para tener justicia hemos nacido."

"Magallanes necesita leyes especiales que permitan a sus habitantes defender sus medios de vida y proveer a sus necesidades que distintas a las del resto del país."

"La autonomía económica y administrativa es la única perspectiva para encaminar nuevamente las actividades de Magallanes hacia el progreso."

Varios de los planteamientos del programa resultaron audaces para la época. En el contexto de un centralismo aparentemente incuestionado, fuerte nacionalismo y temor a la influencia Argentina en la zona en diversos grupos de poder (Martinic, 1992), el PRM abiertamente enfrentaba la alta política desde lo local.

Los principales adversarios políticos del regionalismo fueron, en primer lugar, el Partido Socialista, de cuya ideología existía una experiencia local previa a la conformación del partido homónimo de alcance nacional, en 1933. Éste adquirió gran fortaleza 
y presencia en los numerosos elementos obreros de la región, principalmente los inmigrantes chilotes, instalados en las estancias ganaderas, y en los trabajadores portuarios (Rivas, 2009).

Magallanes había contado, a partir de 1911 , con un poderoso y organizado movimiento obrero, agrupado en la Federación Obrera de Magallanes, el que fue brutalmente desarticulado, a sangre y fuego, en 1915 y 1920 (Vega, 2002 y 2009). Sin embargo, la identidad política de izquierda subsistió subterráneamente en la Provincia hasta su emergencia años después.

En segundo lugar, de gran relevancia también fue el Partido Radical, que durante el período en estudio tuvo un viraje desde las posiciones de centro izquierda propias de la época del Frente Popular (1936-1941), en donde fueron aliados del socialismo a escala nacional, pasando por cierto mareo ideológico durante el gobierno de Juan Antonio Ríos, hasta asumir posturas de centro derecha con Gabriel González Videla, especialmente luego de la aplicación de la llamada 'Ley Maldita' (1948). La fortaleza electoral del radicalismo se encontraba principalmente en sectores de la clase media, especialmente entre funcionarios públicos y privados, ambos con organizaciones gremiales en Punta Arenas (Bustamante, Chávez y Subiabre, 2011).

\section{LA TRAYECTORIA POLÍTICA DEL REGIO- NALISMO AUSTRAL Y SU ROL DENTRO DEL MUNICIPIO}

En líneas generales, se pueden reconocer algunos ejes del desempeño electoral del PRM:

El primer eje tiene que ver con las relaciones políticas establecidas dentro de la centro-izquierda (Frente Popular u otro pacto similar). A pesar de su importancia electoral, e incluso predominio en el municipio, a la larga, el comportamiento del Partido Regionalista de Magallanes viene a terciar la calidad de las relaciones entre el Partido Radical y el Partido Socialista. Cuando hay distanciamiento entre ambos partidos, el regionalismo se vuelve un potencial aliado para uno de los bandos, generándose alianzas altamente pragmáticas y efímeras.

El segundo eje se detecta en la polarización y conflictividad política, acentuada a medida que se aproxima cada elección presidencial y parlamentaria, la que lo obliga a tomar definiciones más ideológicas que las de escala local, produciéndose una distensión posterior al término de dicha elección.

Por último, se observa una fortaleza municipal en su desarrollo, especialmente en Punta Arenas y Porvenir, derivada de su priorización por la administración local. Dicha fortaleza no tiene un correlato en el resultado de las elecciones parlamentarias posteriores a 1933, mucho menos de las presidenciales. 
Una vez constituido el partido, el regionalismo se presentó a la primera elección parlamentaria de la historia magallánica (1933). Los resultados fueron increíbles. El candidato a diputado del regionalismo, Manuel Chaparro Ruminot, salió electo con un $57,9 \%$ de la votación, reflejando la sintonía del partido con la ciudadanía.

Dos años después, esta vez en la primera elección municipal del territorio, nuevamente se logró un exitoso desempeño, al contar con el 51,2\% de los votos, obteniendo el triunfo en dos de las tres alcaldías en disputa (Punta Arenas y Porvenir) y doce de los veintitrés sillones al concejo municipal. (El Magallanes, 10.04.1935)

Luego de la trascendencia electoral lograda en sus primeros años, el PRM transitó hacia una nueva etapa, a partir de la elección presidencial de 1938, en donde por primera vez se hizo patente la polarización que producían esas instancias. Lo reñida y significativa de esa elección tensionó la oferta política del regionalismo. Este intentaba desmarcarse de los fraccionamientos izquierda-derecha y apostaba al consenso en torno a los problemas provinciales como fuente de sufragio.

Las grandes posibilidades de que el vistoso pacto de centro izquierda llamado Frente Popular (Partido Radical, Partido Socialista y Partido Comunista) llegase al poder, presionó no sólo al regionalismo sino que a la sociedad en general, a tomar postura entre el candidato Aguirre Cerda y el derechista ministro de Hacienda Gustavo Ross. Por temor a que una definición oficial generara conflictos dentro de la colectividad, el PRM optó por dar libertad de acción a sus miembros. (EI Magallanes, 22.10.1938)

Aquello, incluso a pesar del descontento que provocó la filtración a la prensa de un telegrama del presidente Alessandri en que respondía a un Senador sobre el descontento en la zona por una permuta poco transparente por parte de una de las grandes estancieras, que "si ud. dice que el pueblo de Magallanes ha perdido la fe en el Gobierno no me preocuparé más de negocios de esa región" (El Magallanes, 20.10.1938). La libertad de acción para sus seguidores se tradujo en un voto muy mayoritario para el candidato del Frente, lo que evitó una mayor tensión post-electoral, algo común en las presidenciales posteriores.

En 1941 correspondieron dos importantes votaciones. En marzo, para las elecciones parlamentarias, el regionalismo presentó la candidatura del ex regidor Comus Meredith, sin alianzas con otros partidos, obteniendo apenas un $19,6 \%$ de los votos, resultando vencedor el abanderado socialista (Juan Efraín Ojeda). Nuevamente quedaba al descubierto la fragilidad del regionalismo en las votaciones 'nacionales' (parlamentarias y presidenciales).

Un mes después, esta vez para las elecciones municipales, el PRM se presentó en conjunto con el Partido Socialista, con el cual se había firmado un pacto pro-acción municipal, el que en menos de un año se dio por terminado. (El Magallanes, 22.03.1941) Para entonces, el Frente Popular estaba roto y los candidatos radicales mostraban grandes posibilidades electorales en la Provincia. Al momento de constituirse el munici- 
pio con los nuevos integrantes, mediante una artimaña política se logra arrebatar el sillón edilicio a los regidores radicales. A continuación, mediante una extensa cita queda al descubierto la estrategia. Hace lectura el regidor radical Guillermo Adriazola:

"Señor Presidente; señores regidores: En el momento de entrar a la votación para designar Alcalde, los regidores radicales desean fundamentar la actitud que van a tomar. Hace dos días [16 de mayo] se firmó en Santiago un pacto radical-socialista, que en cuanto a las Municipalidades de la República expresa que las Alcaldías corresponden al partido mayoritario en la municipalidad respectiva. En las elecciones del seis de abril resultaron elegidos por Punta Arenas cuatro radicales, tres regionalistas y dos socialistas. A este propósito, nuestra Directiva recibió la siguiente notificación anoche: "Señor Presidente de la Junta Provincial Radical.- Presente.Estimado señor: En cumplimiento del pacto celebrado en Santiago, entre las Directivas de los Partidos Radical y Socialista, referente a la constitución de las municipalidades en todo el país, y después de considerar esta situación en reunión del comité regional, se acordó poner en su conocimiento, para los efectos correspondientes, que teniendo nuestro Partido [Socialista] cinco Regidores en la Municipalidad a constituirse, deben los Regidores radicales, conforme al pacto antes anotado, votar por uno de los nuestros. El Regidor Socialista que hemos designado para los efectos de ser designado Alcalde, es el camarada Carlos Turina Blazina. Sin más, saluda a Ud. Andrés Arias - Sec. Regional y Néstor Donoso
Molina, Sec. político». De esta comunicación [continúa Adriazola] se desprende en forma clara y nítida que los señores Turina, Stambuck y Rubio, han ingresado al Partido Socialista. El Partido Radical se consideraba mayoritario en esta Municipalidad hasta el momento de recibir la comunicación leída [...]. Los regidores radicales, al asumir sus funciones, lamentan que un partido como el Regionalista, que ha estado representado eficientemente durante seis años en el municipio, pierda su representación con el ingreso de sus tres regidores al Partido Socialista" (Actas, 18.05.1941).

Queda claro que las negociaciones cupulares de los partidos de alcance nacional respetaban una lógica distinta al contexto local, produciéndose confusas situaciones como la señalada, en donde se muestra una subsunción de lo comunal frente a los intereses 'nacionales'. Esto resultó común en la época, siendo nutrida en pactos efímeros y por momentos incoherentes, caracterizados por un fuerte pragmatismo. El Partido Regionalista de Magallanes no pudo abstraerse de dicha lógica, lo que le provocó a la larga un desgaste y pérdida de credibilidad entre sus votantes.

Como hemos señalado, la década de 1940 traerá una mayor politización y conflictividad en la zona. Tras la prematura muerte del presidente Aguirre Cerda (1941), la campaña electoral consecuente tensionó fuertemente la Provincia. A comienzos de febrero de 1942 , en el seno municipal, la recompuesta alianza radical-socialista increpó en duros términos a los representantes del regionalismo por su apoyo a la candidatura de lbáñez, definida por uno de los regidores como 
'nazi-fascista', frente a lo cual los aludidos intentaron evadir el tema argumentando lo inadecuado de la instancia para esos debates. Consta en las actas, por ejemplo, lo manifestado por el regidor Liborio Carrasco (Partido Socialista):

"En Magallanes, actualmente un grupo con pretensiones de Partido Político, han adherido a la candidatura presidencial de don Carlos Ibáñez del Campo, demostrando con esto su filiación nazi-fascista y, por lo tanto, probando abiertamente que son enemigos de Chile y de la clase trabajadora de Magallanes" (Actas, 12.01.1942).

La agresiva interpelación, especialmente del grupo de regidores socialistas, continuó hasta el día de la votación, impidiendo en la práctica el trabajo municipal por más de tres semanas. El lenguaje dentro del concejo refleja perfectamente lo crispado del ambiente. Otro regidor socialista, Crescencio Soto, afirmó en otra sesión:

"Hoy el Partido Socialista le dice al grupo regionalista y en forma contundente al Alcalde regionalista que el pacto socialista-regionalista de mayo de 1941 ha caducado. Este pacto [municipal] será completamente roto. La camarilla regionalista nazi-fascista a la cual pertenece el Alcalde, destrozó este pacto en forma villana $y$, en esta forma, han iniciado su lucha contra el pueblo de Magallanes" (Actas, 26.01.1942).
Tras lo cual, los aludidos prefirieron abandonar la sala y no continuar con la disputa, de la cual también participaban simpatizantes desde las tribunas, símbolo de la mayor politización social. Llegado el momento de las elecciones, el candidato del pacto radical-socialista, Juan Antonio Ríos, ${ }^{6}$ resultó triunfador. A pesar de esto la situación no se distendió de inmediato. Los regionalistas no se presentaron en la siguiente reunión del concejo, aduciendo razones de salud y trabajo, aunque resulta evidente la causa de la ausencia (Actas, 02.02.1942).

Luego de ello, una vez reincorporados, el obstruccionismo continuó impidiendo la labor edilicia, muestra tal vez de la minusvaloración del rol de las autoridades locales dentro del discurso de lo nacional, puesto que en muchos casos se usó de las sesiones como escenario para grandilocuentes y vagas alocuciones en torno a la 'representación del pueblo', sin abordar los temas que concretamente afectaban a la comuna y la provincia. Un ejemplo del obstruccionismo se presenta a continuación en voz del socialista Crescencio Soto:

"Señor Alcalde: Solicito que se me permita tratar, como cuestión previa, un asunto que ha venido quedando pendiente en sesiones anteriores. En esas sesiones, la representación radical manifestó que mientras el señor Alcalde no cuente con una mayoría para gobernar los destinos de la Comuna, no daría sus

6 Cabe hacer mención que el Partido Socialista presentó otro candidato y que en última instancia el rechazo a lbáñez resultó decisivo en el apoyo a regañadientes a Ríos, quien logró imponerse como candidato de su sector con muchas complicaciones y fricciones. Por supuesto, esta situación no es perceptible en las frases triunfalistas presentes en las actas. 
votos para despachar los asuntos de la tabla. Nosotros los socialistas pensamos lo mismo, y desearíamos saber con qué mayoría cuenta el señor Alcalde para gobernar. $\mathrm{Y}$ en atención a estos pensamientos, vamos a pedir que se postergue la discusión de la tabla" (Actas, 09.02.1942).

Tan incómodo fue el constante cuestionamiento al apoyo a Carlos Ibáñez ${ }^{7}$, y la negativa para abordar cualquier tema propuesto por el Alcalde regionalista (Carlos Turina), que éste decidió no elaborar más la tabla de discusión, puesto que no existía disposición a tratar esos temas:

"Yo por mi parte, que he confeccionado la tabla que contiene asuntos de mucho interés comunal, considero que debe despacharse. Pero como de este debate se desprende que la mayoría de los señores regidores no quiere despachar esta tabla ni otras, declaro que no confeccionaré una nueva porque considero que sería un trabajo inútil" (Actas, 09.02.1942).

Crispaciones como esta serán constantes durante los períodos electorales, especialmente en las presidenciales y las parlamentarias. Se identifica un menor nivel de ideologización y conflictividad respecto a las elecciones locales en los partidos de alcance nacional.
Luego de un par de años sin elecciones, correspondió en 1945 una nueva votación parlamentaria, en donde, increíblemente si se tienen en cuenta los antecedentes que se han presentad acá: el PRM brindó su apoyo al candidato socialista ${ }^{8}$ Juan Efraín Ojeda, quien logró una nueva re-elección. A partir de lo cual termina de delinearse la doble lógica electoral y la funcionalidad de las alianzas. Se puede establecer que el Partido Regionalista de Magallanes dio prioridad al ámbito local y municipal, mientras que los otros partidos fuertes en la zona mostraban mayor interés en las parlamentarias y presidenciales. Eso explica parcialmente lo complejo y aparentemente contradictorio de la trayectoria del PRM aquí en adelante.

Dos años después, respecto a las elecciones municipales de 1947, el grado de pragmatismo vuelve un tanto confuso el esquema de alianzas. El periódico El Socialista, órgano del partido homónimo, resulta útil para reconstruir lo acontecido en la época.

7 Durante el primer gobierno de Ibáñez (1927-1931) Magallanes había logrado el estatus de Provincia. El general había mostrado interés por la zona, e incluso había nombrado a uno de los futuros líderes del regionalismo (M. Chaparro) como Gobernador.

8 A partir de 1943, el socialismo se divide entre la corriente allendista (de oposición al gobierno de Ríos) y el sector oficialista de Marmaduke Grove, que forma una nueva tienda (Partido Socialista Auténtico). 
En enero de 1947, el PRM se incorpora a la agonizante Alianza Democrática ${ }^{9}$, frente a lo cual el semanario publicó:

"La prensa burguesa de la localidad publica con regocijo la noticia de la incorporación del «Partido Regionalista» a la "Alianza Democrática». Si el viejo proverbio «dime con quién andas... te diré quién eres» es tan cierto como viejo, ya sabemos quiénes son los señores Rivera Concha y Brevis, los personeros máximos de la llamada «Alianza Democrática», son gentes que se avergüenzan de pertenecer a los sectores sociales que viven de un salario o sueldo y que estaban locos por relacionarse y codearse con la familia Campos Menéndez y con todos los socios de la tenebrosa «asociación de ganaderos». Con esta alianza del 'regionalismo' y los dirigentes de la 'alianza democrática' el proletariado y el pueblo magallánico no ganarán sino mayores miserias. En cambio, veremos aumentar la lista de las 'familias millonarias"' (El Socialista, 05.01.1947).

Es interesante recalcar que la crítica principal no va dirigida al partido regionalista, sino que al Partido Radical ("millonarios" es un apelativo común para los radicales en la época). En realidad, la relación entre el regionalismo y el socialismo (incluyendo su virulenta prensa) es relativamente armónica. La revisión serial del periódico acerca de cuatro años álgidos (1947-1950), muestra que son muy pocas las alusiones críticas $u$ ofen- sas al regionalismo. Generalmente se conserva un lenguaje más moderado y la crítica siempre se trata respecto de votaciones en el municipio, a diferencia del tratamiento dado a los adversarios del Partido Radical y Partido Comunista, que son constantemente insultados e injuriados. En cuanto al regionalismo y respecto a las votaciones parlamentarias y presidenciales, el bando socialista les consideraba potenciales votantes, especialmente dentro de sus bases más proletarias, a quienes se apelaba directamente mediante la prensa del partido. (El Socialista, 06.03.1949)

Lo cierto es que la incorporación del PRM a la Alianza Democrática no prosperó, puesto que apenas unos meses después el cuadro electoral se mostró totalmente distinto. Nuevamente quedará al descubierto la doble lógica electoral. En las elecciones municipales de 1947, se presentaron situaciones diversas en los tres municipios de la Provincia, lo que posiblemente es un indicio de autonomía de las agrupaciones regionalistas de Porvenir y Puerto Natales respecto de la de Punta Arenas.

Los resultados en Puerto Natales fueron adversos al PRM, a diferencia del Partido Socialista, que obtuvo 4 de los 7 regidores, logrando por ende un alcalde de sus filas. Históricamente el PS se mostró fuerte en Puerto Natales, por la gran presencia de trabajadores ganaderos y de frigorífico, mientras que el regionalismo siempre mostró mayor presencia en los otros territorios de la Provincia.

9 Pacto político derivado del Frente Popular, formado el año 1942 en el marco de la elección presidencial y que se prolongó con muchas dificultades hasta 1947. Fue integrado por radicales, comunistas y grupos menores, como el debilitado Partido Democrático y el Partido Socialista de los Trabajadores. Como ha sido señalado en el pie de página anterior, tras la división del Partido Socialista, el grupo minoritario ("Auténtico") permanecerá en la coalición, mientras que el grupo mayoritario se posicionaría como una virulenta oposición. 
En Porvenir, en cambio, se conformó una coalición electoral sui generis denominada Frente Único (Socialistas, Regionalistas y Radicales Democráticos), en la cual los primeros obtuvieron dos regidores, los segundos un regidor y los terceros otro. ${ }^{10} \mathrm{~A}$ pesar de esto, fruto del pacto, el nominado como Alcalde fue el representante del regionalismo (José del Carmen Gómez). En Punta Arenas, por su parte, la votación socialista solo obtuvo un regidor y no conformó alianza alguna, a diferencia de los regionalistas, que obtuvieron tres regidores electos, mientras que los radicales mostraban su creciente fortaleza con cuatro (El Magallanes, 09.04.1947). Posteriormente, estos últimos suscribieron un pacto con el regionalismo para la conformación municipal.

Frente a este nuevo pacto de gobernabilidad municipal del regionalismo y el radicalismo, la prensa socialista escribió:

"Durante los días que antecedieron a la constitución de la nueva Municipalidad, el Comité Regional del PS celebró varias reuniones con el objeto de considerar el momento político y la situación creada frente al Pacto Político acordado entre el P. Radical y el P. Regionalista y que tanta marejada ha levantado entre el elemento obrero del P. Radical, que ha visto así una vez más traicionado sus intereses por dirigentes que sólo aspiran a encaramarse en los hombros proletarios para obtener los votos que satisfagan sus ambiciones" (El Socialista, 18.05.1947).
Días después, el único regidor socialista en el municipio de Punta Arenas afirmó:

"Es de todos conocida la situación que se ha producido en el Partido Radical-cenista con motivo del pacto radical-regionalista. Sus dirigentes por satisfacer sus ambiciones personales desmedidas han preferido formar un pacto que no contaba ni cuenta con el apoyo de las bases de su partido, contrariando las sanas prácticas de una democracia. Sin embargo, un grupo novedoso de militantes radicales que tienen espíritu y acción del pueblo se han rebelado contra las imposiciones de sus falsos dirigentes provinciales, Este grito de rebeldía es dirigido por el regidor señor Armando Barría Triviño que una vez más ha sido elegido Presidente de la Asamblea de su Partido" (El Socialista, 25.05.1947).

Sin duda el pacto radical-regionalista cambiaba el tablero político en la zona, pues reordenaba las filas, ya que con anterioridad había primado intermitentemente el entendimiento socialista-regionalista. Sin embargo, a pesar de las expectativas, el pacto no entregó los frutos esperados en las parlamentarias de 1949.

En dicha ocasión, el pacto radicalregionalista presentó un candidato (Jorge Cvitanic) muy resistido por dos motivos: era un ex regionalista que se había cambiado al Partido Radical, en una época en que eran adversarios; además, era muy resistido por las bases radicales, que se inclinaban ma-

10 En esa oportunidad, el candidato del Partido Radical Democrático se presentó como miembro del PS. El primero terminó insertándose en el segundo. 
yoritariamente por Armando Barría, quien a diferencia de Cvitanic, tenía una trayectoria dentro del partido y había obtenido la segunda mayoría en la reciente municipal.

Por estrecho margen, el candidato Cvitanic resultó derrotado por el imbatible socialista Juan Efraín Ojeda (quién obtuvo así su cuarto período). Luego de la derrota se produjo un verdadero terremoto político. Inmediatamente después del triunfo, la prensa da cuenta de una situación que hasta el momento no era visible en las fuentes:

"En medio de grandiosas demostraciones de alegría y entusiasmo de los concurrentes que llenaban por completo el local del P.S. Ilegando la cantidad de gente hasta ocupar toda la calle, hicieron uso de la palabra algunos dirigentes del FRAS, del Partido Regionalista, [y otros] [...]. El señor Alejandro López, habló a nombre de los regionalistas conscientes que apoyaron la candidatura del abanderado del Pueblo, c. Juan E. Ojeda [...]" (El Socialista, 18.03.1949).

Al colegir esa información con otras declaraciones, no se trata de que el PRM haya apoyado a última hora al candidato Ojeda, sino que de una fractura en sus bases. Esto se clarifica con noticias posteriores, en donde dirigentes del regionalismo se refieren a un grupo descolgado que utiliza el nombre de 'regionalistas independientes', no representando realmente al partido (La Prensa Austral, 14.07.1952).
Consecuencia de la derrota electoral, se produjo un fuerte quiebre entre el PR y el PRM, en razón de que los primeros alegaron poco apoyo para el candidato común y fuga de votos de las bases regionalistas al candidato Ojeda. Varios días después, un importante miembro del PRM, el alcalde Emilio Salles afirmó al respecto:

"[...] Ahora en plena derrota los radicales le echan toda la culpa a los regionalistas de su rotundo fracaso en las elecciones del seis de marzo, pero ellos olvidan intencionadamente que el candidato desconocido que llevaron a la lucha, no contó con el apoyo de las bases del P. Radical, porque éstas estaban con el señor Barría y que si bien es cierto este señor se inclinó por el candidato impuesto, no ocurrió lo mismo con la gente que lo acompañaba [...]" (El Socialista, 20.03.1949).

Según la sensación post-electoral, las bases regionalistas y radicales no habrían apoyado al candidato del pacto. Esto tendrá consecuencias en el seno municipal. Al momento de sesionar el concejo municipal, a fines de marzo de 1949 , el pacto radical-regionalista que había llevado a Emilio Salles a la alcaldía fue desahuciado y "[...] por culpa de una cláusula secreta que obligó al señor Salles a presentar su renuncia, la cual fue aceptada por los regidores radicales [...]" (El Socialista, 27.03.1949). La renuncia se produjo en un período de confusa subrogancia y deterioro del trabajo municipal. Respecto a lo mismo:

"[...] Después de estos acontecimientos políticos ha quedado totalmente liquidado el pacto entre regionalistas y radicales cenistas. El Partido Regionalista pasa a la 
oposición y junto con el regidor socialista ejercerán una levantada fiscalización de todos los actos de la mayoría radical cenista" (El Socialista, 27.03.1949).

Un año después, el regionalismo se muestra notoriamente debilitado. Se presenta coligado para las municipales con el Partido Socialista Popular ${ }^{11}$ y el Partido Agrario Laborista ${ }^{12}$, pero claramente en posición desmejorada respecto a las elecciones de los años anteriores. A pesar del pacto, el Partido Radical logra quedarse con el sillón edilicio, con la nominación de Felicia Barría Vera (El Magallanes, 03.04.1950).

En el último año comprendido en este estudio, punto clave para entender el debilitamiento del PRM, tiene lugar la elección presidencial de 1952. Los candidatos en disputa eran Salvador Allende (PS), Pedro Enrique Alfonso (PR), Carlos Ibáñez (PAL) y Arturo Matte, este último apoyado por el Partido Conservador, el Partido Liberal, un grupo denominado 'Movimiento de Recuperación Doctrinaria' y el Partido Regionalista de Magallanes. Las fuentes consultadas no permitieron entender la razón de este giro a la derecha, teniendo en cuenta que nunca hubo mayor afinidad con ese sector. Lo cierto es que a juzgar por sus resultados, nunca contó con la simpatía del electorado regionalista. Sin embargo, la prensa si da cuenta del explícito apoyo y trabajo del PRM por el candidato Matte (La Prensa Austral, 21.07.1952).
Igual de explícito fue el rechazo y desmarque de la candidatura de Ibáñez. En una aclaración oficial del partido, presentada a la prensa local, reproducida íntegramente, se afirmó:

"Ante las publicaciones hechas por un grupo de señores que habrían constituido en nuestra ciudad un comité independiente regionalista en apoyo a la candidatura del señor Carlos Ibáñez del Campo, la directiva del Partido Regionalista declara lo siguiente: Que los elementos que constituyen dicho comité presidido por el señor Joaquín Olalla, no son regionalistas por cuanto han dejado de serlo de acuerdo con las disposiciones del reglamento del partido, desde el momento mismo en que no han acatado el acuerdo que obliga por igual a todos los regionalistas de apoyar la candidatura de don Arturo Matte. El Partido Regionalista debe declarar, una vez más, que nadie, fuera de los miembros autorizados de su directiva pueden tomarse el nombre de la institución para realizar publicaciones de ninguna especie, mucho menos cuando tales publicaciones obedecen al propósito desleal y despreciable de sembrar confusión entre aquellas personas que, por falta de información, pueden ser sorprendidos con las especies propaladas por estos elementos desplazados, por diversas causas, de las filas del partido. Con esta declaración deseamos dejar las cosas en su verdadero lugar, a la vez que advertir a nuestros correligionarios el peligro que para la

\footnotetext{
11 Una nueva división se produjo en 1948 en el Partido Socialista, respecto a la posición sobre la 'Ley Maldita' que pretendía ilegalizar al Partido Comunista. La facción anticomunista fue expulsada pero logró mantener el nombre de Partido Socialista de Chile, quienes rechazaron la ley, pasaron a denominarse Partido Socialista Popular.

12 Partido creado en 1945 -tras la fusión del Partido Agrario y el Partido Laborista- de difícil definición ideológica. Encarnaba un proyecto reformista y nacionalista, con tintes corporativistas (Garay, 1989). Partido comúnmente asociado con el General Carlos Ibáñez del Campo.
} 
unidad del partido significa la labor desquiciadora de elementos amargados y oportunistas que no tienen ni han tenido jamás los méritos suficientes para destacarse en nuestra actividades partidarias.- Punta Arenas, 5 de julio 1952.- Firmado, Luis Stambuck S., Presidente; Nicolás Mihovilovic, Secretario General" (La Prensa Austral, 07.07.1952).

Queda claro que las divisiones vistas en el año 1949 se mantenían años después, lo cual sin duda es un factor para entender la irrelevancia electoral del partido a mediados de 1950 . Lo que no resulta explicable es lo acontecido con posterioridad a dicha elección presidencial.

El escrutinio dio cuenta de un impresionante apoyo al candidato Ibáñez en la provincia, muy por sobre los demás contendores. Se deben comparar los 7.548 votos por Ibáñez frente al escuálido resultado de Matte, de sólo 637 (La Prensa Austral, 05.09.1952). El Partido Regionalista fue incapaz de captar votos significativos para Matte en la zona, dando muestra del debilitamiento y la distancia con las preferencias de las bases.

Finalmente, como resultado del desastre electoral, el PRM se adentró en una muy confusa reconversión ideológica, que vuelve a ligarla al Ibañismo, pero ciertamente sin el protagonismo y relevancia de las décadas de 1930 y 1940.

\section{MUNICIPIO Y REGIONALISMO: ALGU- NAS CONCLUSIONES.}

El Partido Regionalista de Magallanes, a lo largo de los años estudiados, mostró una clara vocación municipalista, otorgándole prioridad a su participación en dicha Corporación. La aparentemente confusa política de alianzas con diversas entidades del espectro ideológico, debe analizarse desde la óptica de sus objetivos. Esa preminencia de lo local en su seno significó un bajo desempeño (salvo en 1933) en cuanto a las elecciones parlamentarias y presidenciales, como también una cierta subsunción a las aspiraciones de sus aliados. Esa doble lógica política, privilegio de la municipal en desmedro de las otras elecciones, le permitió al PRM mantener una cuota de poder importante en el plano local por dos décadas, frente a partidos con un inmenso despliegue territorial en el país.

La revisión de las actas municipales de Punta Arenas de gran parte del período comprendido, permite afirmar que el PRM mantuvo una coherencia respecto a sus postulados. La participación de los miembros del partido se caracterizó por enfocarse en el mejoramiento de la gestión, la defensa de la autonomía municipal, una mejor provisión de servicios públicos, los debates en torno al desarrollo regional y la resolución de los principales problemas ciudadanos. Los temas locales más relevantes en el período fueron el mejoramiento del agua potable, la utilización de los sitios urbanos baldíos, la adecuada iluminación y el aseguramiento de una cuota de la carne producida para el mercado interno, entre otros. 
Ese espíritu estuvo también presente en la mayoría de los regidores de los otros partidos. Sin embargo, a medida que aumentaba el grado de politización y distanciamiento en las posturas ideológicas al interior del Concejo, la labor edilicia se resentía notoriamente.

Por ejemplo, en el período previo a la elección presidencial de 1942, en el cual se cuestionó el apoyo a lbáñez por parte del PRM, las sesiones municipales se desvirtuaron completamente, pasando a ser más bien una tribuna de confrontación ideológica con bajo desempeño deliberante. Como hemos señalado, en esa oportunidad prácticamente se perdió un mes entero de gestión municipal. A ese respecto, los partidarios del regionalismo, probablemente por mantener cierta distancia de la polarización en torno al criterio de clase, supieron mantener su perfil de gestores locales, entendiendo lo que significaba el municipio. Más allá de la propia definición ideológica, desmarcada del eje izquierda-derecha, se defendió el municipio como lugar para buscar soluciones favorables a la ciudadanía, mostrándose contrarios a su politización (en el sentido de partidización). (Actas, 12.01.1942)
Paradojalmente, ese mismo perfil medró su capacidad de influir en un plano más amplio, erosionándose su capacidad de convocatoria, por no contar con una oferta (o discurso) adecuado para el contexto, lo que restó atractivo a la experiencia regionalista. Por otra parte, el programa del regionalismo a fines de los cuarenta había perdido validez, puesto que:

"el planteamiento del federalismo era impracticable; la cuestión de la aduana, estaba resuelta formalmente por el decreto de mayo de 1933, aunque la experiencia práctica señalara su ineficacia; la cuestión agraria había adelantado y mucho en su superación por la aprobación de la ley 6.152 [...]" (Martinic, 1988: 246).

En cierto sentido, el regionalismo militante se mostró incapaz de modificar y actualizar sus postulados dentro de su propia matriz localista y municipalista. En cambio, sí demostró la capacidad de convocatoria y la fuerza política de las reivindicaciones locales en su lucha contra el centralismo.

\section{REFERENCIAS}

Fuentes Primarias. Actas, informes y prensa del período.

Actas Corporación Municipal de Punta Arenas (1931 - 1942). Punta Arenas: Imprenta El Magallanes.

Diario El Socialista, Punta Arenas.

Diario El Magallanes, Punta Arenas.

Diario La Prensa Austral, Punta Arenas. 
Navarro, L. (1907), Censo Jeneral de población i edificación, industria, ganadería i minería del Territorio de Magallanes, tomo I, Punta Arenas: Imprenta El Magallanes.

Periódico La Voz de Magallanes, Punta Arenas.

Programa del Partido Regionalista de Magallanes. Publicado en La Voz de Magallanes el 18 de junio 1932, Punta Arenas.

\section{Fuentes Secundarias}

Bustamante C., Chávez C. y K. Subiabre (2011). Historia de la Sociedad de Empleados de Comercio de Magallanes durante los años 1911-1930 y su importancia para el desarrollo social-local. Tesis para optar al título profesional de Profesor de Historia y Ciencias Sociales, Universidad de Magallanes. Punta Arenas.

Calderón, J. (1936). Historia de la Industria ganadera en el Territorio de Magallanes. Boletín del Ministerio de Agricultura, No10, oct-dic., pp. 1-47.

Garay, C. (1990). El Partido Agrario Laborista: 1945-1958. Santiago: Editorial Andrés Bello.

López, E. (2010), La hacienda pública en Chile: 1824-1860. Una aproximación a la realidad provincial. Documento de Trabajo, proyecto State Building in Latin America. Consultado el 10 de febrero de 2013. Disponible en http://www.statebglat.upf.edu/

Martinic, M. (1988). Magallanes 19211952: Inquietud y crisis. Punta Arenas: Ediciones La Prensa Austral.
Martinic, M. (1992). Historia de la Región Magallánica. Vol. II. Punta Arenas: Ediciones Universidad de Magallanes.

Rivas, C. (2009). El Partido Socialista de Chile en la Región de Magallanes y Antártica chilena: Visión histórica de los militantes más antiguos. Seminario de Título para optar a Profesor de Historia y Ciencias Sociales, Universidad de Magallanes. Punta Arenas.

Salazar G. (1998). El municipio cercenado. En G. Salazar y J. Benítez (comp.), Autonomía, espacio y gestión: El municipio cercenado. Santiago: LOM ed.

Salazar, G. (2005). Construcción de Estado en Chile (1800-1837). Democracia de los "pueblos", militarismo ciudadano. Golpismo oligárquico. Santiago: Editorial Sudamericana.

Valenzuela, A. (1977), Polítical brokers in Chile. Local government in a centralized polity, Durham N.C.: Duke university Press.

Valenzuela, E. (1999). Alegato Histórico Regionalista. Santiago: SUR Ediciones.

Vega, C. (2002). La masacre en la Federación Obrera de Magallanes. El movimiento obrero patagónico-fueguino hasta 1920. Punta Arenas: Editorial Atelí.

Vega C. (2009). 1915: La primera gran huelga natalina. Punta Arenas: Editorial Atelí. 